\title{
POLES IN PHARMACY - SOURCE OF KNOWLEDGE AND PREVALENCE OF OVER THE COUNTER USAGE
}

\author{
EWA BANDURSKA*, JUDYTA ZALESKA and MARZENA ZARZECZNA-BARAN \\ Public Health and Social Medicine Department, Medical University of Gdansk, Poland
}

\begin{abstract}
Self-medication is a procedure that is increasingly eagerly chosen by people all over the world, especially in common conditions (e.g. infections of upper respiratory tract). The main objective of this study was to determine the prevalence of self-medication and identify the sources of knowledge used by Polish society in searching for information on OTC medicines. The study was conducted in the group of 252 Internet users at working age (18-64 years) living in Poland (women $\mathrm{n}=208 ; 82.5 \%$, men $\mathrm{m}=44 ; 17.5 \%$ ) and used an original questionnaire consisting of 29 questions available on Internet from December 2016 to February 2017. According to the obtained results, self-treatment was undertaken by $90.08 \%$ of Poles. Using OTC products was most prevalent among people with university education $(\mathrm{p}=0.01)$ and without children $(\mathrm{p}=0.03)$. Most popular source of knowledge on self-medication was own experience $(n=149 ; 59.1 \%)$ and pharmacists' advice ( $\mathrm{n}$ $=148 ; 58.7 \%)$. TV commercials were considered as unimportant for most of the respondents $(54.3 \%)$. Young women (18-26 years) most often used the Internet to search for information about OTC drugs $(\mathrm{p}=0.03)$, young male trusted own experience $(p=0.03)$ and men from older age groups $(p=0.04)$ advice of a pharmacist. Selfmedication can be characterized as prevalent in Poland. People with lower levels of education used OTC medicines less often and therefore might benefit from stronger support of professionals.
\end{abstract}

Keywords: respiratory tract infections, Self Care, Nonprescription Drugs

The definition of 'self-treatment' is not uniform. According to the World Health Organization (WHO) that concept consists of three terms (1):

- Self-care - considered as attitudes and actions which contribute to the maintenance of health, such as: taking part in health programs (promoting health and preventing diseases), leading a healthy lifestyle (2);

- Self-management - actions undertaken by chronically ill patients who are able to recognize their symptoms and take appropriate actions (for example in conditions like diabetes, asthma) (1);

- Self-medication - independent use of OTC (Over the Counter) medicines without consulting a doctor (3).

\section{Prevalence of self-medication in Poland and other countries}

Self-medication is particularly eagerly used by society in common diseases that are minor and which symptoms are easy to diagnose. A classic example of such condition, are upper respiratory tract infections (4).

According to the survey conducted by the Center for Public Opinion Research (CPOR), using
OTC medicines is common in Poland $-81 \%$ of Poles use it at least once a year. Every fourth drug that is bought in Poland is OTC type (5). Poles are not used to consult their doctor to choose OTC drugs. According to the Central Statistical Office (CSO) survey, approximately $90.4 \%$ of the households being a pharmacy customer buy at least one drug without consulting a physician (6). Studies of CPOR also indicate that $68 \%$ of adult Poles use medical products to relieve symptoms of cold and flu that can be obtained without a prescription (14). The sale of OTC drugs in Poland in 2013 amounted to 9.6 billion PLN (7). In 2014, Poland was ranked as the second (after Germany) country in Europe in terms of size of OTC market (8). Using OTC products is even more popular in South Africa and the United States. Using so-called home treatments is most common in Great Britain, China, and USA (9).

\section{Risks and benefits of self-medication}

Properly performed self-treatment can undoubtedly bring benefits. If proceeded correctly, it might reduce demand for medical services and as a result - direct medical costs. Instead of visiting a

* Corresponding author: e-mail: ebandurska@gumed.edu.pl 
GP, common symptoms can be consulted with a pharmacist, who can help to choose proper drug and provide necessary information. Self-medication also increases the patients' health consciousness and makes them more responsible for their health and lifestyle.

Table 1. Baseline characteristics of the study group $(n=252)$.

\begin{tabular}{|c|c|c|}
\hline Parameter & Female $\mathrm{n}(\%)$ & Male n (\%) \\
\hline \multicolumn{3}{|c|}{ Age } \\
\hline $18-26$ & $167(80.29 \%)$ & $20(45.45 \%)$ \\
\hline $27-35$ & $16(7.69 \%)$ & $6(13.64 \%)$ \\
\hline $36-44$ & $10(4.01 \%)$ & $7(15.91 \%)$ \\
\hline $45-54$ & $13(6.25 \%)$ & $5(11.36 \%)$ \\
\hline $55-64$ & $2(0.96 \%)$ & $6(13.64 \%)$ \\
\hline SUM & $208(100 \%)$ & $44(100 \%)$ \\
\hline \multicolumn{3}{|c|}{ Place of residence } \\
\hline Village & $43(20.67 \%)$ & $8(18.18 \%)$ \\
\hline City to 10 ths. residents & $11(5.29 \%)$ & $1(2,27 \%)$ \\
\hline City $10-50$ ths. residents & $45(21.63 \%)$ & $8(18.18 \%)$ \\
\hline City 50-100 ths. residents & $17(8.17 \%)$ & $2(4.55 \%)$ \\
\hline City $100-500$ ths. residents & $68(32.69 \%)$ & $20(45.45 \%)$ \\
\hline City $>500$ ths. residents & $24(11.54 \%)$ & $5(11.36 \%)$ \\
\hline SUM & $208(100 \%)$ & $44(100 \%)$ \\
\hline \multicolumn{3}{|c|}{ Marital status } \\
\hline Single & $166(79.81 \%)$ & $30(68,18 \%)$ \\
\hline Divorced & $4(1.92 \%)$ & $0(0 \%)$ \\
\hline Married & $37(17.79 \%)$ & $13(29.55 \%)$ \\
\hline Widow/widower & $1(0.48 \%)$ & $1(2.27 \%)$ \\
\hline SUM & $208(100 \%)$ & $44(100 \%)$ \\
\hline \multicolumn{3}{|c|}{ Education level } \\
\hline Elementary & $0(0.00 \%)$ & $4(9.09 \%)$ \\
\hline Vocational & $2(0.96 \%)$ & $4(9.09 \%)$ \\
\hline High school & $84(40.38 \%)$ & $20(45.45 \%)$ \\
\hline University & $122(58.65 \%)$ & $16(36.36 \%)$ \\
\hline SUM & $208(100 \%)$ & $44(100 \%)$ \\
\hline \multicolumn{3}{|c|}{ Number of children } \\
\hline 0 & $174(83.65 \%)$ & $27(61.36 \%)$ \\
\hline 1 & $16(7.69 \%)$ & $5(11.36 \%)$ \\
\hline 2 & $17(8.17 \%)$ & $7(15.91 \%)$ \\
\hline 3 and more & $1(0.48 \%)$ & $5(11.36 \%)$ \\
\hline SUM & $208(100 \%)$ & $44(100 \%)$ \\
\hline \multicolumn{3}{|c|}{ Economic status where 1 - is poverty; 5 - life in good economic conditions } \\
\hline 1 & $1(0.48 \%)$ & $1(2.27 \%)$ \\
\hline 2 & $16(7.69 \%$ & $5(11.36 \%)$ \\
\hline 3 & $86(41.35 \%)$ & $21(47.73 \%)$ \\
\hline 4 & $74(35.58 \%)$ & $12(27.27 \%)$ \\
\hline 5 & $31(14.90 \%)$ & $5(11.36 \%)$ \\
\hline SUM & $208(100 \%)$ & $44(100 \%)$ \\
\hline
\end{tabular}


Self-treatment or more specifically - self-medication, can also cause a number of negative consequences, such as taking wrong drugs due to incorrect self-diagnosis (10). On a public scale, self-medication can contribute to an increase in the number of drug-induced conditions $(7,11)$.

Self-medication can be a safe procedure if patients seek for professional advice and get support in decision-making process on choosing OTC products (for example from a pharmacist or a doctor) (12). Apart from professional sources of knowledge on OTC products, patients are also provided with information through the media, among other commercials. Television advertising is a commonly used mean to communicate information - within only 1 week in October 2015 in Polish TV as many as 3.804 adds were broadcasted, fewer in case of medical devices and dietary supplements (282 and 182, respectively) (13). TV advertisements are popular but it's reliability is discussible, especially in case of dietary supplements $(14,15)$.

In this paper we have undertaken an analysis of an increasingly widespread phenomenon, which is self-medication for the upper respiratory tract diseases / infections with use of OTC medicines. The analysis includes not only the prevalence (with respect to demographic features) but also the sources of knowledge chosen and trusted by Poles of working age deciding to undertake self-medication. The work is therefore a multi-threaded topic.

\section{Objectives}

The main objective of this study is to determine prevalence of self-medication with OTC drugs and to identify sources of knowledge used and trusted by Polish society. The study also sets specific objectives:

Determination of the impact of demographic features on using OTC drugs in self-medication for the upper respiratory tract diseases/infections.

Determination of the impact of demographic features on the choice of source of knowledge about OTC products.
Determination of the impact of television advertising on the choice of OTC medication.

\section{EXPERIMENTAL}

\section{Study population}

The study was conducted in the group of 252 Internet users at working age (between 18 and 64 years of age) living in Poland, who voluntarily agreed to participate in the study. The distribution of demographic characteristics in the study group was typical for studies on using the Internet for information considering health issues - the majority were women $(n=208 ; 82.5 \%)$. Men constituted $17.5 \%$ of the study group $(n=44)$. The dominant type of education in women was university education $(\mathrm{n}=122$, $58.65 \%)$, and in men high school $(\mathrm{n}=20 ; 45.45 \%)$. As much as $20.23 \%$ of the study group were people living in rural areas. Other demographic data are presented in Table 1.

\section{Method}

An anonymous survey was conducted as a cross-sectional research with the use of original questionnaire among Poles of working age (18-64 years for male, 18-59 years for female). The questionnaire was available electronically (Google form) between December 2016 and February 2017, but only for people who met the baseline criteria considering age. After one week the initial analysis of responsiveness to the survey was conducted. As much as 198 surveys were collected. Taking into account a satisfying number of participants and the fact that $100 \%$ of surveys were completed correctly, the study was continued without any changes. Only those individuals $(\mathrm{n}=$ 186) who had previously confirmed that they used OTC drugs were included in part of the study related to types of sources of knowledge.

All calculations were carried out by means of Microsoft Excel spreadsheet and STATISTICA, StatSoft, Inc. ver. 8.0. statistical package (data analysis software system). The relationship between analyzed data was determined with use of Chi2 test.

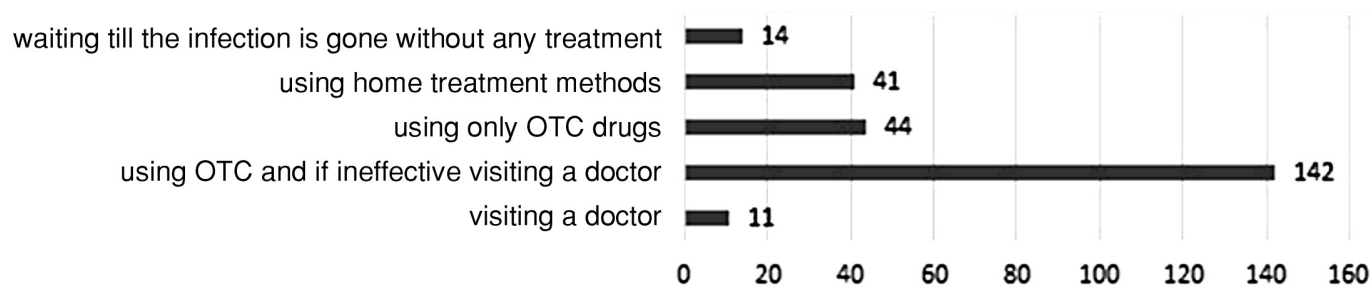

Figure 1. Actions taken after observing symptoms of upper respiratory tract infection $(\mathrm{n}=252)$ 
In all the calculations the statistical significance level was set to $\mathrm{p}<0.05$.

\section{RESULTS}

Prevalence of self-treatment, including using OTC drugs

As much as $90.08 \%$ of respondents $(n=227)$ declared using self-treatment for upper respiratory tract infections (with use of OTC drugs or home methods). The most common method was self-medication with OTC medicines $(\mathrm{n}=142,56.35 \%)$ followed by a visit to a GP if they are ineffective. The next $17.6 \%$ of people used OTC medicines without counseling a doctor at all and $16.27 \%$ used only home treatment methods - complete data in Figure 1.

\section{Impact of demographic factors on self-medica- tion}

Using OTC medicines was found to be popular no matter the demographic features. Women more often than men used OTC medicines in case of occurring symptoms of infection of upper respirato- ry system, nevertheless the observed differences were not statistically significant $(p=0.195)$. Age also did not influence significantly using OTC medicines $(\mathrm{p}=0.1593)$, nor the place of residence $(\mathrm{p}=$ $0.51)$ or marital status $(p=0.0942)$. Although economic status did not influence significantly the prevalence of using OTC drugs $(\mathrm{p}=0.0673)$ - it was possible to notice that using OTC products was more popular among people with better economic status.

It was also noticed that people with university education used OTC medicines significantly more often than people with other types of education ( $\mathrm{p}=$ 0.0115 ). Also, the number of children in the family influenced significantly the decision to buy OTC drugs - people who had no children were more likely to undertake self-medication $(77.1 \%$ of respondents without children decided to do so) - see Table 2 .

\section{Sources of knowledge about OTC medicines}

When indicating the source of knowledge used to obtain information about OTC products, respondents could provide more than one answer.

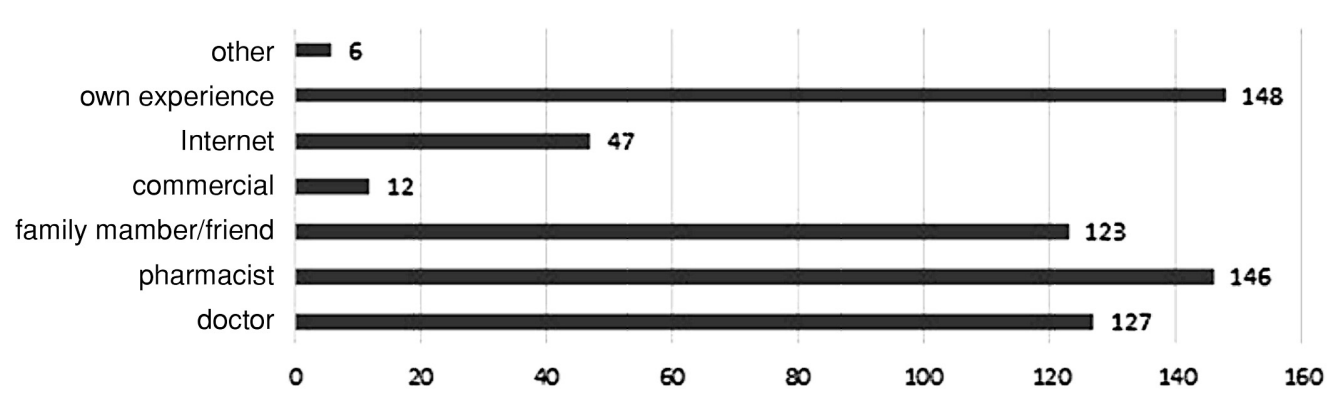

Figure 2. Sources of knowledge and advice on the choice of drugs used for upper respiratory tract infections $(\mathrm{n}=252)$

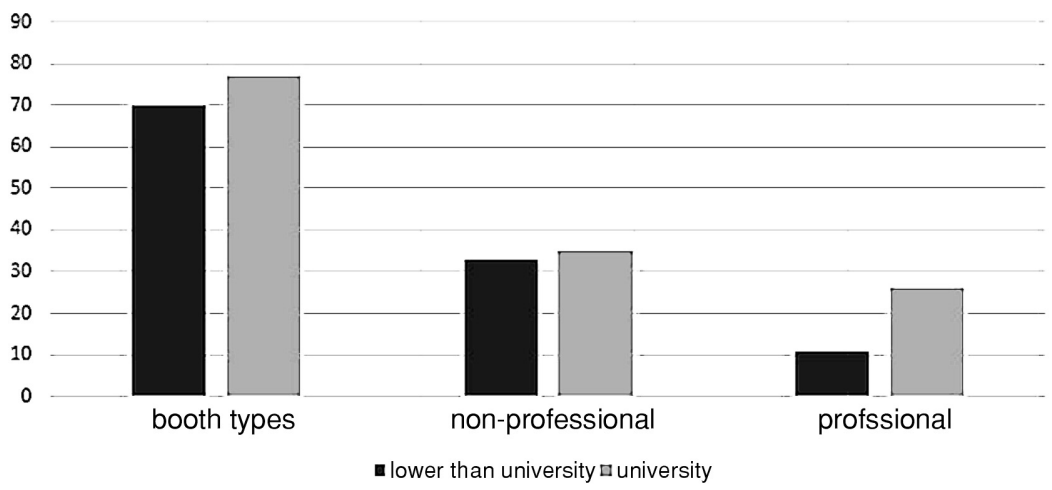

Figure 3. Sources of knowledge used by people with different levels of education 
Poles trusted mostly own assessment and pharmacist's advice. Own experience (understood as own experience with a specific drug or own assessment based on individual knowledge) was indicated most often ( $\mathrm{n}=149 ; 59.1 \%$ ), followed directly by an advice of a pharmacist $(\mathrm{n}=148 ; 58.7 \%)$. Slightly fewer respondents indicated a doctor $(\mathrm{n}=127$; $50.4 \%)$ and relatives or friends $(n=123 ; 48.8 \%)$. Internet and commercials were the least popular sources of information on OTC medicines (Figure 2).

Table 2. Impact of demographic features on using OTC medicines with results of Chi2 test.

\begin{tabular}{|c|c|c|c|}
\hline \multirow{2}{*}{ Parameter } & \multicolumn{2}{|c|}{ Using OTC medicines } & \multirow{2}{*}{ Chi2; p } \\
\hline & YES & NO & \\
\hline \multicolumn{4}{|c|}{ Sex } \\
\hline Female & 157 & 51 & \multirow{2}{*}{$\begin{aligned} \text { Chi } 2 & =1.721218 \\
p & =0.1895\end{aligned}$} \\
\hline Male & 29 & 15 & \\
\hline \multicolumn{4}{|c|}{ Age } \\
\hline $18-26$ & 143 & 43 & \multirow{5}{*}{$\begin{array}{c}\text { Chi2 }=7.381633 \\
p=0.1938\end{array}$} \\
\hline $27-35$ & 15 & 7 & \\
\hline $36-44$ & 8 & 9 & \\
\hline $45-54$ & 13 & 5 & \\
\hline $55-64$ & 6 & 2 & \\
\hline \multicolumn{4}{|c|}{ Place of residence } \\
\hline Village & 36 & 15 & \multirow{6}{*}{$\begin{aligned} \text { Chi } 2 & =3.767816 \\
p & =0.5833\end{aligned}$} \\
\hline City to 10 ths. residents & 9 & 3 & \\
\hline City $10-50$ ths. residents & 39 & 14 & \\
\hline City 50-100 ths. residents & 14 & 5 & \\
\hline City $100-500$ ths. residents & 70 & 18 & \\
\hline City $>500$ ths. residents & 18 & 11 & \\
\hline \multicolumn{4}{|c|}{ Marital status } \\
\hline Single & 149 & 47 & \multirow{4}{*}{$\begin{aligned} \text { Chi } 2 & =5.531299 \\
p & =0.1368\end{aligned}$} \\
\hline Divorced & 1 & 3 & \\
\hline Married & 35 & 15 & \\
\hline Widow/widower & 1 & 1 & \\
\hline \multicolumn{4}{|c|}{ Education } \\
\hline Elementary & 1 & 3 & \multirow{4}{*}{$\begin{aligned} \text { Chi } 2 & =9.495394 \\
p & =0.0234\end{aligned}$} \\
\hline Vocational & 2 & 4 & \\
\hline High school & 76 & 28 & \\
\hline University & 107 & 31 & \\
\hline \multicolumn{4}{|c|}{ Number of children } \\
\hline 0 & 155 & 46 & \multirow{4}{*}{$\begin{array}{l}\text { Chi2 }=9.166 \\
p=0.02716\end{array}$} \\
\hline 1 & 11 & 10 & \\
\hline 2 & 17 & 7 & \\
\hline 3 and more & 2 & 3 & \\
\hline \multicolumn{4}{|c|}{ Economic status } \\
\hline 1 & 0 & 2 & \multirow{5}{*}{$\begin{aligned} \text { Chi2 } & =8.764620 \\
p & =0.0673\end{aligned}$} \\
\hline 2 & 16 & 5 & \\
\hline 3 & 84 & 23 & \\
\hline 4 & 63 & 23 & \\
\hline 5 & 23 & 13 & \\
\hline
\end{tabular}




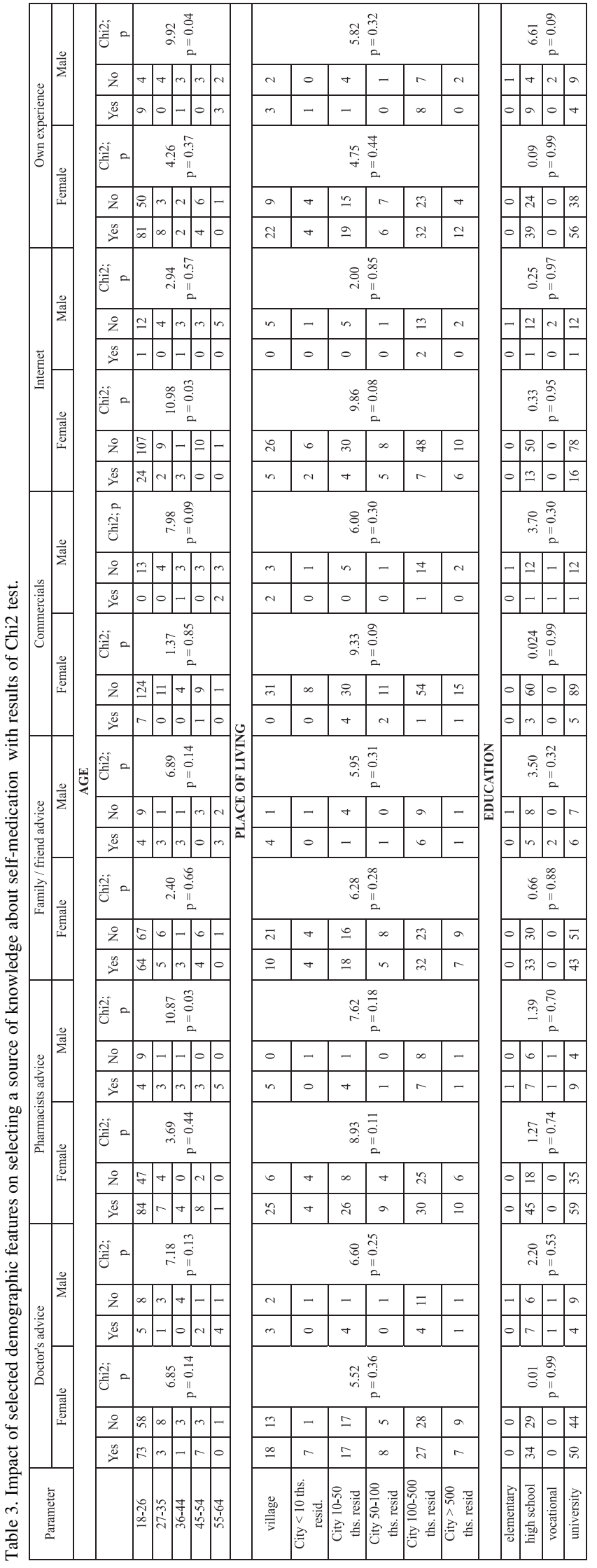

For over half of people using OTC medicines $(54.3 \%)$ advertising was unimportant and only occasionally affected their choice of the drug. Only $20.97 \%$ of respondents $(n=48)$ using OTC drugs considered advertisements as important or the most important factor when choosing specific product. The observed properties were not gender ( $p$ $=0.22)$, age $(\mathrm{p}=0.79)$ or marital condition specific $(p=0.095)$. Nevertheless, it is worth noting that no impact of commercial was more often mentioned by people with high school or university education $(\mathrm{p}=0.058)$.

\section{The impact of demographic factors on the choice of sources of knowledge about self-medication}

In most cases, demographic factors did not have a statistically significant impact on the source of self-medication knowledge (see Table 3).

In all groups, the most popular was own expertise and pharmacists. Taking into account the advice of a pharmacist was especially common among male of older age groups $(p=0.03)$. When analyzing using professional (doctor, pharmacist) and non-professional (own experience, Internet, commercial, family) sources and the level of education (university and lower levels separately) it can be noticed that people with higher education were more likely to use only professional sources ( $\mathrm{n}=25$ vs. $\mathrm{n}=9$ respectively), but at the same time using only non-professional sources was similarly prevalent in both groups ( $\mathrm{n}=33 \mathrm{vs}$. $\mathrm{n}=35$ respectively) - general differences between choosing professional and non-professional types of knowledge were not statistically significant ( $\mathrm{p}$ $=0.12)-$ Figure 3 .

It is worth noting that although the study was conducted in the population of Internet users, it turned out that the Internet was not a popular source of knowledge in choosing OTC drug. Nevertheless, women from the youngest age group (18-26 years) chose this source of knowledge statistically significantly more often than other women ( $p$ $=0.03)$. In the case of men, age had no 
significant impact on the frequency of choosing this source of information $(p=0.57)$.

As mentioned, own expertise was an important source of knowledge - especially in the group of women $(60.51 \%)$. Nevertheless, the age of women had no significant impact on using own expertise in choosing OTC drug $(\mathrm{p}=0.37)$. The situation was different in the case of men. Men from the youngest age group (18-26 years) were most likely to consider own experience as relevant $(\mathrm{p}=0.04)$.

\section{DISCUSSION}

Self-medication is a procedure that is increasingly eagerly chosen by Poles, as evidenced by the 2016 Center for Public Opinion Research report on the use of OTC drugs (16). It was found that $89 \%$ of adult Poles used OTC drugs and dietary supplements, $68 \%$ of them used OTC drugs to control the symptoms of upper respiratory tract infections and $68 \%$ for pain and inflammation. When comparing these results with similar study of Center for Public Opinion Research conducted in 2010, an increase in popularity of drugs used for cold, flu, and sore throat can be noticed - the difference is over $13 \%$ (17).

According to international studies, women were more engaged in using the Internet to search for health-related information $(18,19)$. The majority of the volunteers who decided to participate in the presented study and therefore were interested in its' subject - were female $(82.5 \%)$. High educationlevel was found to be strongly related to higher rates of using Internet by Baker et al. (20). In the study by Hesse et al. (21) it was determined that Internet users searching for health-related information were most often women from younger age groups, with high income and university education. Similarly, in the presented study, the dominant type of education of female was university level.

According to the presented study, adult Poles with university level of education were more likely to use OTC medicines in comparison to people with lower levels of education. Also, people with higher levels of education were less likely to follow information from advertisements when choosing OTC product (significance level $\mathrm{p}=0.058$ ). When comparing using professional and non-professional type of information it appears that people with higher education more often used only professional type information. People with lower levels of education used non-professional or both types of sources of information (although there were no significant differences between groups). Similarly, in the study by
Cham et al. (22) it was found that level of education is correlated with better awareness of the safe use of OTC drugs, especially in case of painkillers. This might indicate that Poles, especially those with lower levels of education, might benefit from stronger support and advice when experiencing upper respiratory tract infections. Less common use of OTC medication among people with lower levels of education may indicate their uncertainty about own judgment and fear to make a mistake that might result in adverse events. This results in limited possibilities to benefit from self-medication. Similar results were obtained in the study by Villako et al. who noticed that people with elementary school education were more likely to buy prescribed drugs, not OTC (23).

Decision to use a specified source of information is related to its' reliability. In the study by Zarzeczna-Baran et al. (24) it was found that the most reliable source of information for Poles is a pharmacist $(62.2 \%)$, but at the same time - they also tend to rely on TV advertisement (50.6\%). In the presented study the most often presented approach was using professional and non-professional types of sources at the same time $(58.37 \%)$. According to the study by Piecuch et al. patients seldom ask pharmacists for advice although, according to the survey on trust to public professionals, $87 \%$ of them trust pharmacists and their opinions. The main reason for not asking pharmacists for an advice was long waiting line in a pharmacy and lack of confidentiality (25). As a result, Poles decide to use non-professional sources of information that are easily accessible and anonymous. According to the result of the presented study, in approximately $86.12 \%$ cases Poles choose either using only non-professional type of knowledge $(27.76 \%)$ or they use both types at the same time $(58.36 \%)$.

In the study by Chaniecka et al. (26) it was found that as much as $50 \%$ of Poles determine their attitude towards commercials as positive $(51.9 \%$ of women and $48.2 \%$ of men). Similarly, the results of Hartman et al. (27) indicate that $64.2 \%$ of respondents use the specific OTC drug for cold because they knew it from an add.

In the presented study, Poles did not consider advertising as an important source of knowledge about OTC drugs (especially those with university education). Meanwhile, medicines are among the most advertised products. In universal Polish TV channels (TVP1, TVP2, Polsat, TVN) there were 196.072 commercials of medicinal remedies in 2014, what puts this group of products on the first place with a share of $22.7 \%$ of adds (for comparison: 
food $-18.5 \%$ ). Commercials of medicinal remedies are broadcasted also on TV channels dedicated for children - in 2014 there were 10.406 such adds (13). The fact that such a widely used marketing tool is not highly trusted could be surprising, but it is supported also in studies of other authors. In a study by Syrkiewicz-Świtała et al. (28) it was proven that Poles consider advertisements as indifferent to their decision to choose an OTC drug (53.5\%) and 1/3 of them denied using advertisement information at all, which can be compared with the results of this study (occasionally rely on adds $-50.6 \%$, never $-30.4 \%$ ). Self-medication is a popular phenomenon, and its' spread will likely increase in the course of increasing access to the Internet and other sources of knowledge, especially in common diseases, like upper respiratory tract infections. There is a strong distinction in terms of the sources of knowledge chosen by Poles, which may indicate that they are still looking for an adequate and comfortable one. The most available sources - TV and Internet - are not the most popular ones and are not considered reliable. This creates a space for professional staff to support Poles with reliable data and therefore - to increase safety of self-treatment.

Self-medication in infections of the upper respiratory tract is characterized by a significant prevalence among population of working age, it is chosen by $90.08 \%$ of Poles out of which $74.15 \%$ use OTC medicines. Using OTC medicines is most popular among people with university level of education and having no children. The sources of knowledge selected by Poles are varied. The most popular source of knowledge about OTC medicines is own experience and advice of a pharmacist. Selecting a source of knowledge in a limited extent depends on demographic factors - younger women more often use the Internet, younger men relay on own experience and older male use pharmacist's advice in choosing OTC drugs. TV advertisement is not a popular source of knowledge about OTC drugs. Poles most often decide to use more than one source of knowledge, which might indicate they still look for reliable help.

\section{REFERENCES}

1. http://www.wsmi.org/about-self-care-and-selfmedication/what-is-self-medication/ (accessed on 26.01.2017)

2. Krajewski-Siuda K., Chmura R., Łach K.: J. Health Sci. 4, 9 (2014).

3. http://www.biznes.newseria.pl/news/polacy-corazczesciej,p436698641 (accessed on 10.10.2017).
4. Hughes C., McElnay J., Fleming G.: Drug Saf. 24, 1027 (2001).

5. Central Statistical Office of Poland: Health status of the Polish population in 2014. (2016).

6. Central Statistical Office of Poland: Healthcare in households in 2013. (2014).

7. Świeczkowski D., Merks P., Jaguszewski M.: Farm. Pol. 72, 286 (2016).

8. http://www.obywatelezz.pl/uploads/2016/05/ FOZZ-Raport-Odpowiedzialne-i-nowoczesnesamoleczenie.pdf (accessed on 15.09.2017).

9. http://www.wsmi.org/wp-content/data/pdf/ wsmibro3.pdf (accessed on 03.10.2017).

10. Matoulkova P., Dosedel M., Ruzkova B., Kubena A.: Acta Pol. Pharm. 70, 333 (2013).

11. http://apps.who.int/medicinedocs/pdf/ h1462e/ h1462e.pdf (accessed on 15.09.2017).

12. Piecuch A., Makarewicz-Wujec M., Kozłowska-Wojciechowska M.: Int. J. Clin. Pharm. 39, 70 (2017).

13. http://www.krrit.gov.pl/Data/Files/_public/ Portals/0/komunikaty/leki-i-suplementy/2015_ emisja-przekazow-handlowych-produktowzdrowotnych-lekow-w-programach-telewizyjnych.pdf (accessed on 11.10.2017).

14. http://www.rynekzdrowia.pl/Farmacja/Pracujanad-projektem-ograniczenia-reklam-suplementowdiety, 163037,6.html (accessed on 02.11. 2017).

15. https://www.gif.gov.pl/pl/decyzje-i-komunikaty/decyzje/decyzje?ida[3]=5 (accessed on 02. 11.2017).

16. Center for Social Opinion Research: Communicate no. BS/143/2010. (2010).

17. Center for Social Opinion Research: Communicate no. 158/2016. (2010).

18. Bidmon S., Terlutter R.: J. Med. Internet Res. 17, e156 (2015).

19. Amante D., Hogan T., Pagoto S., English T., Lapane K.: J. Med. Internet Res. 17, e106 (2015).

20. Baker L., Wagner T., Singer S., Bundorf M.K.: JAMA. 289, 2400 (2003).

21. Hesse B., Nelson D., Kreps G., Croyle R.T., Arora N.K. et al.: Arch. Intern. Med. 165, 2618 (2005)

22. Cham E., Hall L., Earnst A., Weiss S.: South Med. J. 95, 529 (2002).

23. Villako P., Volmer D., Raal A.: Acta Pol. Pharm. 69, 335 (2012).

24. Zarzeczna-Baran M., Bandurska E., PęgielKamrat J., Lewandowska A.: Ann. Acad. Med. Ged. 43, 77 (2013).

25. Piecuch A., Kozłowska-Wojciechowska M.: Int. J. Clin. Pharm. 35, 225 (2013). 
26. Chaniecka K., Czerw A.: Hygeia Public Health. 48, 509 (2013).

27. Hartman M., Lichtański P., Klimacka-Nawrot E., Donocik K., Błońska-Fajfrowska B.: Ann. Acad. Med. Sil. 66, 12 (2012).
28. Syrkiewicz-Świtała M., Holecki T., Mazur M.: Handel wewnętrzny. 3, 285 (2015).

Received: 09.11.2017 